\title{
O impacto da cultura organizacional na gestão do conhecimento para a inovação de processos em serviços
}

\section{The impact of organizational culture on knowledge management for service process innovation}

\author{
Herivelton Luís Bueno Carneiro ${ }^{1}$, Rosalvo Ermes Streit ${ }^{2}$ \\ 1 Universidade Católica de Brasília - UCB, Brasília, DF, Brasi. ORCID: https://orcid.org/0000-0002-1337-2212 \\ 2 Universidade Católica de Brasília - UCB, Brasília, DF, Brasi. ORCID: https://orcid.org/0000-0003-4479-7966
}

Autor para correspondência/Mail to: Herivelton Luís Bueno Carneiro, hvelton@msn.com

Recebido/Submitted: 04 de dezembro de 2020; Aceito/Approved: 02 de março de 2021

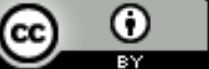

Copyright (C) 2021 Carneiro \& Streit. Todo o conteúdo da Revista (incluindo-se instruções, política editorial e modelos) está sob uma licença Creative Commons Atribuição 4.0 Internacional. Ao serem publicados por esta Revista, os artigos são de livre uso em ambientes educacionais, de pesquisa e não comerciais, com atribuição de autoria obrigatória. Mais informações em http://revistas.ufpr.br/atoz/about/submissions\#copyrightNotice.

\begin{abstract}
Resumo
Introdução: a inovação é um diferencial competitivo importante no contexto da era do conhecimento e da transformação digital. A gestão do conhecimento, por sua vez, promove, por meio da criação e compartilhamento de ideias, um ambiente favorável à inovação. Neste contexto, é importante que os elementos da cultura organizacional que impactam a gestão do conhecimento para a inovação sejam conhecidos de forma que possam ser melhor trabalhados. Método: por meio de revisão de literatura e pesquisa bibliográfica foram identificados os elementos da cultura organizacional que impactam a gestão do conhecimento para a inovação de processos em serviços. Após, foi aplicado questionário de pesquisa junto a funcionários de uma instituição financeira de grande porte para a análise dos elementos identificados na literatura. Resultados: os resultados permitiram identificar quais elementos da cultura organizacional atuam como estimuladores e quais se constituem em barreiras à gestão do conhecimento para a inovação de processos em serviços na organização pesquisada. Conclusão: com maior adaptabilidade, calibragem mais adequada na aversão ao risco, concessão de maior autonomia aos funcionários e lideranças que valorizem as iniciativas de criação e compartilhamento de conhecimento, e mantenham uma comunicação efetiva, pode-se melhorar a prontidão da organização para a inovação de seus processos de serviços.
\end{abstract}

Palavras-chave: Cultura organizacional; Gestão do conhecimento; Inovação; Compartilhamento de conhecimento.

\begin{abstract}
Introduction: innovation is an important competitive differential in the era of knowledge and digital transformation. Knowledge management, in turn, promotes, through the creation and sharing of ideas, an environment favorable to innovation. In this context, it is important to know the elements of the organizational culture that impact knowledge management for innovation so that they can be better worked. Method: It identifies through literature review and bibliographic research the elements of organizational culture that impact knowledge management for service process innovation. Afterward, it applies a survey questionnaire to employees of a large financial institution, to analyze the elements identified in the literature. Results: the results identify which elements of the organizational culture act as stimulators and constitute barriers to knowledge management for the innovation of processes in services in the researched organization. Conclusion: with greater adaptability, adequate calibration in risk aversion, granting greater autonomy to employees and leaders who value initiatives for the creation and sharing of knowledge, and maintain effective communication, the organization's readiness can improve to innovate its service processes.
\end{abstract}

Keywords: Organizational culture; Knowledge management; Innovation; Knowledge sharing.

\section{INTRODUÇÃO}

O cenário de negócios atual está sujeito a fatores desafiadores, como a entrada rápida de novos concorrentes no mercado e o surgimento de produtos, serviços e tecnologias disruptivas que, muitas vezes, impactam os modelos tradicionais de atuação. Tais fatores, principalmente aqueles relacionados a novas tecnologias, estão intimamente conectados com o elemento digital presente na rotina das pessoas. A crescente influência dessas tecnologias relaciona-se diretamente a processos de transformação digital e de inovação.

O objetivo deste estudo foi identificar quais elementos da cultura organizacional impactam a Gestão do Conhecimento (GC) para a inovação de processos em serviços. Esta pesquisa se desenvolve junto a unidades de negócios especializadas em atendimento presencial e digital de uma instituição financeira. Neste contexto, as inovações de processos em serviços são as mais viáveis, levando-se em consideração que não se tratam de unidades que trabalham com desenvolvimento de produtos e, tampouco, unidades que determinam as estratégias do negócio, mas que atuam com foco na prestação do serviço de atendimento ao cliente. As instituições financeiras atuam num mercado que está sofrendo de maneira bastante acentuada o impacto da transformação digital. Esse impacto se dá em especial na experiência do cliente, por isso a importância de se buscar a melhoria contínua dos processos na prestação de serviços por meio da inovação.

Cabe destacar que "a importância da inovação no setor de serviços e da contribuição do setor de serviços para o crescimento econômico é crescentemente reconhecida", conforme indicado no Manual de Oslo (Organização para Cooperação Econômica e Desenvolvimento, 2005, p. 46), e que "as inovações de processo incluem métodos 
novos ou significativamente melhorados para a criação e a provisão de serviços" (Organização para Cooperação Econômica e Desenvolvimento, 2005, p. 59). Ainda sobre a inovação de serviços, Souza Neto, Santos, e Orlandi (2014, p. 507) afirmam que "em serviços com muita interatividade, a equipe que efetivamente provê o serviço é parte da experiência do cliente e, portanto, parte da inovação".

Existem diversos trabalhos que buscam demonstrar o impacto da cultura organizacional na GC para a inovação. Todavia, esses estudos se ativeram ao conceito de inovação como um todo, sem se aprofundar num tipo específico. Dada a importância do setor de serviços e das inovações em processos para esse setor, identificou-se uma lacuna de estudos que busquem verificar, de modo mais específico, quais elementos da cultura organizacional impactam a GC para a inovação de processos em serviços.

\section{REFERENCIAL TEÓRICO}

\section{Cultura organizacional}

Observa-se na literatura que o conceito de cultura é bastante amplo e diverso e depende da perspectiva em que é analisado. Hofstede, Hofstede, e Minkov (2010) afirmam que a cultura é sempre um fenômeno coletivo, porque é, pelo menos em parte, compartilhada com pessoas que vivem ou viveram no mesmo ambiente social, que é onde ela foi aprendida. Os autores ainda colocam que a cultura consiste nas regras não escritas do jogo social. É a programação coletiva da mente que distingue os membros de um grupo ou categoria de pessoas de outros.

Schein (2017, p. 1) diz que "cultura é um fenômeno dinâmico que nos cerca em todas as horas, sendo constantemente desempenhada e criada por nossas interações com outros". O autor também afirma que "o aspecto mais intrigante da cultura como conceito é que ela nos aponta os fenômenos que estão abaixo da superfície, que são poderosos em seu impacto quase invisíveis e comportam um grau considerável de inconsciência" (Schein, 2017, p. 8) .

Com relação à cultura organizacional, segundo Hofstede et al. (2010), é a programação coletiva da mente que distingue os membros de uma organização dos outros. Segundo Cameron e Quinn (2006), a manifestação mais óbvia da cultura é o comportamento explícito dos seus membros. Em uma organização, é a maneira pela qual as pessoas interagem, o esforço que elas investem na organização e a extensão em que inovações ou atividades são toleradas ou incentivadas. Isso é, muitas vezes, descrito como 'a maneira como as coisas são por aqui'.

A cultura organizacional influencia o desempenho corporativo e, em especial, a inovação e a GC. Cameron e Quinn (2006), por exemplo, afirmam que a maioria dos estudiosos e observadores organizacionais reconhece que a cultura organizacional tem um efeito poderoso no desempenho e na eficácia de longo prazo das organizações. Schein (2017, p. 270) também afirma que "construir uma organização efetiva é uma questão de mesclar diferentes subculturas, encorajando a evolução de metas, línguas e procedimentos comuns para solução de problemas".

A cultura pode estabelecer barreiras à inovação ou pode facilitar o processo, portanto, cabe à liderança promover a gestão da cultura organizacional com intuito de buscar maior eficácia para a empresa e sua sustentabilidade no longo prazo. "Uma funcao-chave da liderança e estabelecer o tipo de cultura que e necessária na empresa e, em seguida, modelar a cultura existente para que se ajuste a esse tipo ideal" (Dias, 2013, p. 97).

\section{Gestão do conhecimento}

Nonaka e Takeuchi (1997, p. 63) distinguem conhecimento de informação e definem o primeiro como "crença verdadeira justificada". Afirmam que "a informação é um meio ou material necessário para extrair e construir o conhecimento". Esses autores ressaltam, ainda, que "o conhecimento em si e formado por dois componentes dicotômicos e aparentemente opostos - isto e, o conhecimento explícito e o conhecimento tácito"Takeuchi e Nonaka (2008, p.19).

O conhecimento explícito pode ser expresso em palavras, números ou sons, e compartilhado na forma de dados, fórmulas científicas, recursos visuais, fitas de áudio, especificações de produtos ou manuais. O conhecimento explícito pode ser rapidamente transmitido aos indivíduos, formal e sistematicamente. O conhecimento tácito, por outro lado, não e facilmente visível e explicável. Pelo contrário, e altamente pessoal e difícil de formalizar, tornando-se de comunicação e compartilhamento dificultoso. As intuições e os palpites subjetivos estão sob a rubrica do conhecimento tácito. O conhecimento tácito esta profundamente enraizado nas ações e na experiência corporal do indivíduo, assim como nos ideais, valores ou emoções que ele incorpora (Takeuchi \& Nonaka, 2008, p.19).

Nonaka e Takeuchi (1997, p. 68) apontam "que o conhecimento é criado por meio da interação entre o conhecimento tácito e o conhecimento explícito". A interação entre os conhecimentos tácitos e explícitos possibilita que a organização desenvolva novos conhecimentos e que eles sejam compartilhados entre seus membros. É importante ressaltar que o diferencial competitivo das empresas reside bem mais no conhecimento tácito, aquele saber que o indivíduo carrega consigo e que muitas vezes nem mesmo o próprio se dá conta de que o detém. Esse é um tipo 
de conhecimento difícil de ser registrado e até mesmo transmitido e, portanto, também é difícil de ser copiado ou imitado. Takeuchi e Nonaka (2008, p.119) afirmam que "muitos administradores hoje admitiriam prontamente que a criação do conhecimento tem importância para suas empresas, especialmente se trabalharem para empresas de alta tecnologia que dependem da inovação".

Todavia, a criação do conhecimento enfrenta determinadas barreiras, que podem ser tanto de natureza individual como de natureza organizacional. Isso porque o processo de compartilhar conhecimento depende essencialmente de relações humanas, e essas são complexas. Nesse sentido, é necessário que as organizações se esforcem para superar essas barreiras e promovam a criação e o compartilhamento de conhecimento (Takeuchi \& Nonaka, 2008, p.119). "A chave e estruturar uma organização de forma que a criação do conhecimento prossiga mais efetiva e eficientemente, desmontando tantas barreiras individuais e organizacionais quanto possível" (Takeuchi \& Nonaka, 2008, p.113).

Davenport e Prusak (2003, p. 117) afirmam que "há muitos fatores que inibem a transferência do conhecimento". Os autores reforçam o papel determinante da cultura organizacional na GC ao declararem que "para que se mantenha livre o fluxo do conhecimento, a cultura organizacional precisa ser extraordinária" (Davenport \& Prusak, 2003, p. 132).

A GC permite que as organizações possam criar conhecimento e compartilhá-lo, o que é importante para que as inovações possam surgir e gerar diferencial competitivo para a empresa. Todavia, para esse processo ocorrer de forma adequada é essencial que exista uma cultura organizacional que favoreça um ambiente criativo e inovador.

\section{Inovação}

Segundo o Manual de Oslo (Organização para Cooperação Econômica e Desenvolvimento, 2005), a inovação pode ocorrer em quatro frentes: produto, processo, marketing e organizacional. O Manual de Oslo (Organização para Cooperação Econômica e Desenvolvimento, 2005, p. 47) destaca a diversidade das inovações em serviços e afirma que "as atividades de inovação em serviços também tendem a ser um processo contínuo, consistindo em uma série de mudanças incrementais em produtos e processos".

Souza Neto et al. (2014, p. 520) afirmam que "as características dos bem-sucedidos inovadores em serviços são: investimentos no desempenho dos empregados, inovação operacional contínua, inovação estratégica contínua, modelo de negócios que facilite a escalabilidade". Os autores também destacam o que seriam barreias culturais para a difusão da inovação: "são as punições por erros, uma cultura que premia a conformidade, a lealdade à gerência, que significa obediência à autoridade" (Souza Neto et al., 2014, p. 685).

Para Tigre (2014, p. 2074) "a introdução de uma inovação em uma empresa não acontece no vácuo, pois exige uma estrutura operacional e gerencial adequada, assim como rotinas, procedimentos e uma subjacente cultura organizacional". Tigre (2014, p. 1441) ainda afirma que a inovação depende "principalmente de concatenações mais complexas dos conhecimentos e ideias que formam a estrutura das organizações". Nessa mesma direção, Porto (2013, p. 93-94) destaca que "torna-se mais relevante o papel da ação gerencial e do aprendizado organizacional, que têm relação direta com a capacidade de inovação da empresa".

Cabe destacar que o papel da gestão da inovação para as organizações atualmente ganha importância na medida em que as empresas implementam suas estratégias para a transformação digital, ressaltando que "transformar-se para a era digital exige que o negócio atualize sua mentalidade estratégica, muito mais que sua infraestrutura de TI" (Rogers, 2017, p. 103).

\section{METODOLOGIA}

A instituição financeira objeto desta pesquisa é identificada como Banco Beta. Compuseram o público-alvo da pesquisa funcionários da organização lotados em duas tipologias distintas de unidades de negócios, que atuam diretamente na prestação de serviços e atendimento aos clientes. A primeira é composta por agências especializadas em atendimento presencial, e a segunda são escritórios especializados no atendimento digital. Essas unidades foram escolhidas por possibilitarem a mensuração do impacto da cultura organizacional na GC para inovação de processos em serviços.

A pesquisa bibliográfica foi realizada levando-se em consideração o tema da pesquisa e o seu objetivo de identificar quais elementos da cultura organizacional se constituem barreiras ou estímulos à GC e à inovação. Foram realizadas buscas na base Scopus, no Portal de Periódicos da Capes com os termos "knowledge management" AND innovation AND culture* $^{*}$ AND organization*, somente nas palavras-chave dos documentos, de modo que os resultados da pesquisa restassem mais assertivos e alinhados com o tema de interesse. Foram identificados 102 documentos, os quais tiveram seu título e resumo analisados com o intuito de verificar a aderência ao objetivo da pesquisa. Na sequência, após a seleção de 20 artigos considerados relevantes para este estudo, realizou-se a leitura e fichamento desses documentos. 
A coleta de dados foi realizada através de um questionário com perguntas abertas e fechadas. As questões foram elaboradas buscando identificar, de acordo com os elementos culturais encontrados na revisão de literatura, quais constituem barreiras ou estímulos à GC para a inovação na organização pesquisada. Para tanto, foram elaboradas 17 questões, sendo uma delas aberta e as demais fechadas. As duas primeiras perguntas buscavam identificar a percepção dos respondentes sobre a relação existente entre a cultura organizacional e a GC, e desta com a inovação de processos em serviços. Os respondentes foram orientados a considerar na resposta as organizações em geral e não especificamente o Banco Beta. Nas demais questões foi solicitado que considerassem nas respostas a organização onde trabalham.

Foram enviadas mensagens eletrônicas (e-mail) para dois mil funcionários do Banco Beta, selecionados aleatoriamente, com o link de acesso ao questionário da pesquisa, entre os dias 28 de abril de 2019 e 07 de maio de 2019. Em 16 de maio de 2019 o acesso ao questionário foi fechado e os resultados coletados. Obtiveram-se 338 respostas, $17 \%$ do total de questionários enviados, todas elas válidas.

\section{RESULTADOS}

\section{Pesquisa bibliográfica}

Com relação ao impacto da cultura organizacional na GC, Choy, Lee, Cheung, e Shim (2005) concluíram que a partir dos resultados do perfil da cultura não só é possível avaliar a prontidão e as lacunas da cultura organizacional para a GC, mas também permite que a organização acompanhe continuamente a mudança de cultura durante a implementação da GC. Yee, Tan, e Ramayah (2017), por sua vez, construíram um modelo para examinar as relações entre estilo de liderança, cultura organizacional, GC e capacidade de absorção, por entenderem que isso era necessário para acelerar o processo de tomada de decisão. Os autores Chang e Lin (2015), em sua pesquisa, buscam explorar a relação entre a cultura organizacional e a intenção do processo de GC do indivíduo, o resultado encontrado foi de que as culturas orientadas para resultados e para o trabalho têm efeitos positivos na atitude do empregado no processo de GC (criação, armazenamento, transferência e aplicação), enquanto uma cultura rigidamente controlada tem efeitos negativos. Essa afirmação é corroborada pelo estudo realizado no Banco Comercial da Etiópia por Assefa, Garfield, e Meshesha (2012), cujo objetivo era identificar elementos da cultura organizacional e investigar como esses elementos culturais promovem ou dificultam o compartilhamento de conhecimento entre os funcionários do Banco.

A pesquisa de Ahmadi, Rajabbaigy, e Moghaddar (2012) teve como finalidade determinar a relação entre cultura organizacional e GC, concluindo que, quando há uma forte cultura organizacional, a GC pode ser melhor realizada e que a cultura organizacional também tem um papel importante na criação de um forte sistema de GC. Os autores Al-Adaileh e Al-Atawi (2011) afirmam que existe uma correlação estatisticamente significativa entre a cultura organizacional e troca de conhecimento como um todo, que enfatiza o papel efetivo dos fatores da cultura organizacional na troca de conhecimento. A pesquisa desenvolvida por Lamproulis (2007) explica as diferentes maneiras pelas quais o espaço organizacional e a tecnologia aumentam a produção de conhecimento que se transforma em inovação. Essa pesquisa conclui que, principalmente, é a cultura de uma organização que determina como o espaço físico e a tecnologia desenvolvem a produção de conhecimento que leva a projetos inovadores. Outra pesquisa que busca compreender como os artefatos culturais em organizações afetam a GC foi desenvolvida por Ajmal e Helo (2010) em empresas finlandesas que trabalham com a gestão de projetos, e os resultados demonstraram que sem uma cultura organizacional apropriada os valiosos ativos de conhecimento podem ser irremediavelmente perdidos quando um projeto é concluído. A pesquisa desenvolvida por Paliszkiewicz (2010) revelou que a GC requer uma liderança forte e que o líder traduz como e sob quais condições a empresa compete agora e no futuro. Rivera-Vazquez, Ortiz-Fournier, e Flores (2009) afirmam que o conhecimento é um dos ativos mais valiosos dos negócios e um importante fator competitivo.

O único trabalho com foco exclusivo no impacto da cultura organizacional na inovação, desenvolvido por Naqshbandi e Tabche (2018), propõe um modelo de mediação que evidenciasse a interação entre a liderança, capacidade de absorção e cultura de aprendizagem organizacional em inovação aberta.

O impacto da GC na cultura organizacional foi abordado em dois trabalhos. No primeiro, os autores propõem que a relação entre os fatores que influenciam a aprendizagem por compartilhamento fornece evidências sobre como as organizações podem promover a cultura baseada na transferência de conhecimento. O uso contínuo do conhecimento não diminui o valor, como outros insumos, essas foram as principais conclusões do estudo de Pohontu, Istrate, e Herghiligiu (2016). Corfield e Paton (2016) encontraram resultados que mostraram que, embora a cultura fosse reconhecida como um conceito complexo, os programas de GC eram muitas vezes simplisticamente destinados a 'mudar a cultura'.

Dentre os trabalhos que abordaram o impacto conjunto da GC e da cultura organizacional na inovação, os autores Abdessadak, Achelhi, e Reklaqui (2018) buscaram discutir o papel que a GC desempenha no processo de sustentabilidade da empresa e descobrir a relação entre a cultura organizacional, inovação e GC. Entre os resultados encontrados se destaca o achado dos autores com relação ao conhecimento tácito, que desempenha 
um papel relevante nas organizações que priorizam a inovação. Os autores concluem que cultura e GC são as duas principais dimensões que afetam a inovação e, consequentemente, a performance organizacional. A pesquisa desenvolvida por Zia e Shafiq (2017) discute a relação entre o processo de criação do conhecimento e a inovação, e também o papel da cultura organizacional nessa relação. Os autores ressaltam o papel da cultura organizacional na formação de uma relação entre inovação e GC e também sugerem que uma cultura conducente e solidária pode desempenhar um papel vital na implementação de estratégias de inovação e GC.

Os autores Lin, Ho, e Lu (2014) discutem as correlações entre clima de inovação organizacional e GC, concluindo que existem correlações notáveis entre cultura corporativa e clima de inovação organizacional, assim como fortes correlações entre GC e cultura corporativa, e efeitos mediadores da cultura corporativa na GC e na inovação organizacional. Com o objetivo de examinar os efeitos diretos e indiretos da cultura organizacional, GC e aprendizado organizacional sobre inovação, Abdi et al. (2018) desenvolveram sua pesquisa com empresas iranianas do setor automobilístico. O estudo explicitou que cultura organizacional e GC influenciaram a inovação organizacional, todavia, a GC não foi considerada mediadora na relação entre cultura organizacional e inovação organizacional. Nesse estudo, os autores utilizam os tipos de cultura propostos por Cameron e Quinn (2006), ou seja, uma abordagem diferente da utilizada por Lin et al. (2014). Contudo, de maneira geral os resultados apontam para uma mesma conclusão: culturas abertas, flexíveis, em que os colaboradores têm maior autonomia estão num estado de prontidão maior para aplicação das ferramentas de GC e, consequentemente, mais aptas a inovar; porém, culturas fechadas, burocráticas, com excesso de normas e controle rígido, inibem o compartilhamento de conhecimento e tem baixa performance em inovação.

Investigar a relação entre cultura organizacional, estilo de liderança, aprendizagem organizacional e inovação organizacional foi o objetivo da pesquisa de Tang e Yeh (2015), que chegaram à conclusão que o estilo de liderança não tem impacto direto na capacidade de inovação. Analisar o impacto da inovação como variável de mediação para a relação de GC e da cultura organizacional para o desempenho da empresa foi o objetivo estabelecido por Puryantini, Rofikotul, Tjahjadi, et al. (2018) ao desenvolverem seu estudo num instituto de pesquisas da Indonésia. Os autores destacam que a cultura organizacional pode afetar a inovação, seja para encorajá-la ou inibi-la. Para ter sucesso em inovar e adotar avanços tecnológicos, as empresas devem ser capazes de atender aos requisitos em termos do comportamento das relações internas e externas ao mesmo tempo. Os autores Donate e Guadamillas (2011) analisaram de que forma fatores organizacionais, como valores culturais, liderança e práticas de recursos humanos, influenciam práticas de exploração de conhecimento e inovação. Os autores concluem que fatores organizacionais e práticas de GC são reforçados mutuamente, melhorando o desempenho da inovação. Sugere-se que, embora as práticas de GC sejam importantes para fins de inovação, quando determinados facilitadores - fatores organizacionais para superar as barreiras humanas à GC - são adequadamente estabelecidos, a capacidade de inovação da empresa pode ser mais bem explorada.

Assim, o levantamento bibliográfico permitiu analisar o estado do corpo de conhecimento sobre a relação entre GC, inovação e cultura organizacional. A maior parte dos estudos analisados confirma uma estreita ligação entre os três temas, ao mesmo tempo em que é possível inferir que a cultura organizacional exerce um papel definitivo para o êxito tanto da GC como da inovação, visto que os artefatos culturais da organização podem se apresentar como facilitadores ou como barreiras ao compartilhamento de conhecimento e ao ambiente favorável à criatividade e, consequentemente, à inovação.

\section{Elementos culturais que impactam a gestão do conhecimento para a inovação}

Na revisão de literatura foi possível identificar os elementos da cultura organizacional que impactam a GC para a inovação. É importante ressaltar que algumas pesquisas relacionam os elementos culturais à inovação sem transitar diretamente pela GC, no entanto, conforme pôde ser percebido, os processos de GC (criação e compartilhamento) são importantes para a inovação. Portanto, percebe-se que os elementos que impactam a inovação também o fazem com a GC, e o inverso também é verdadeiro, ou seja, elementos que impactam a GC também afetam a inovação.

A lista a seguir sintetiza os elementos culturais identificados, com base no que foi encontrado na revisão de literatura e na pesquisa bibliográfica:

a) Adaptabilidade: é o elemento que define se uma cultura organizacional é aberta ou resistente a mudanças e quebra de paradigmas. Em culturas fortes, comum em empresas constituídas ainda na era analógica, também pode estar presente a institucionalização, que é quando a empresa passa a ser valorizada por si só e não pelo que produz, são características que dificultam a mudança cultural e o processo de GC para a inovação;

b) Aversão ao Risco: abrange as características culturais que definem a forma como a empresa trata a aversão ao risco, se existe punição a erros e falhas, se os funcionários estão submetidos a normas e controles rígidos;

c) Autonomia: diz respeito à autonomia com que os funcionários podem atuar, se as estruturas hierárquicas e de supervisão são rígidas ou flexíveis; 
d) Colaboração: elemento diretamente relacionado à criação e ao compartilhamento de conhecimento, mediante uma relação de confiança e reconhecimento; e

e) Liderança: representa a atuação do líder na promoção da GC para inovação, inclusive no que diz respeito à efetividade do processo de comunicação na organização.

Cabe destacar que a nomenclatura para os elementos culturais identificados pode variar de um autor para outro, todavia, a classificação levou em consideração a essência de cada elemento. É importante observar que pode haver interseção entre esses elementos, haja vista que são componentes que se complementam e interagem entre si.

\section{Coleta de dados}

Os resultados foram organizados por intermédio de gráficos de barras divergentes empilhadas, pois, segundo N. B. Robbins, Heiberger, et al. (2011), facilitam a comparação das respostas dos participantes em diferentes categorias demográficas. Esse tipo de gráfico permite a visualização de todas as perguntas vinculadas a um mesmo elemento cultural em uma só imagem, otimizando a análise e comparação das repostas coletadas. Os percentuais de respondentes que concordam com a afirmação são dispostos à direita da linha zero dos gráficos abaixo, enquanto os percentuais que discordam são dispostos à esquerda (Figura 1). 


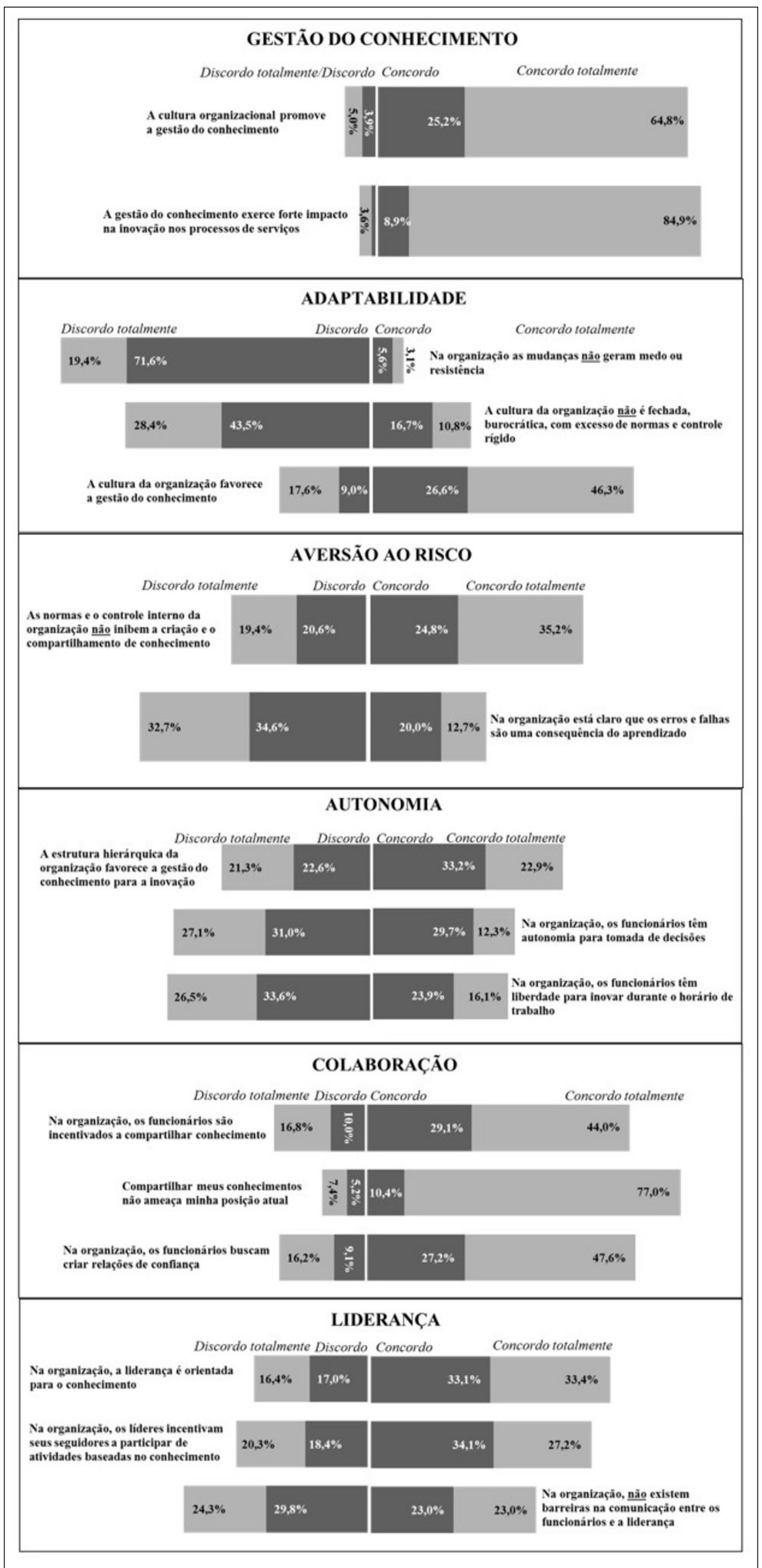

Figura 1. Resultados da pesquisa.

Fonte: Elaborado pelos autores (2020). 
Os resultados da pesquisa permitiram verificar quais elementos da cultura organizacional atuam como barreiras ou estímulos para a GC, com foco na inovação, para o Banco Beta, bem como propor ações para reforçar os elementos culturais que estimulam a GC para inovação de processos em serviços e ajudar na superação daqueles que se colocam como barreiras.

Os resultados do bloco "gestão do conhecimento" demonstram que os participantes da pesquisa percebem de forma clara a relação entre a cultura organizacional, a GC e a inovação dos processos em serviços. Takeuchi e Nonaka (2008) afirmam que a cultura corporativa tem o poder de produzir ou frear a criação do conhecimento e, consequentemente, a inovação.

Nos demais blocos, entre os elementos culturais pesquisados, a colaboração se destacou como o que mais estimula a GC para a inovação. Os respondentes demonstraram que existem incentivos para que o conhecimento seja compartilhado, ao mesmo tempo em que não há receio entre os participantes de que compartilhar o conhecimento possa ameaçar sua posição na organização. Os funcionários também buscam criar relações de confiança entre si, o que favorece a criação de um ambiente propício ao compartilhamento do conhecimento. Trata-se de um elemento cultural importante, Choy et al. (2005) afirmam que a criação de uma cultura de compartilhamento de conhecimento é fundamental para o sucesso da GC. Rivera-Vazquez et al. (2009) concluíram que a produção e o compartilhamento de conhecimento têm sido reconhecidos como a chave para a inovação, ainda, segundo Donate e Guadamillas (2011), as práticas de GC, entre elas o compartilhamento de conhecimento, melhoram o desempenho da inovação.

Com relação ao elemento cultural liderança, nos resultados das perguntas fechadas, ficou evidenciado que existe uma liderança orientada para o conhecimento na organização e que os líderes incentivam seus seguidores a participar de atividades baseadas no conhecimento, fatores que atuam como estimuladores da GC para a inovação. Segundo Donate e Guadamillas (2011), a liderança orientada para o conhecimento baseia-se na promoção da confiança e da aprendizagem, e no empoderamento de seguidores, seu desenvolvimento em conjunto com o uso de práticas de gestão do conhecimento melhora o desempenho, em termos de inovação. Yee et al. (2017) afirmam que a liderança está relacionada de forma indissociável da cultura organizacional, que precisa proporcionar um ambiente favorável ao desenvolvimento e atuação de líderes que promovam a GC e a inovação.

Todavia, foram apontadas dificuldades na comunicação entre os funcionários e a liderança, vale ressaltar que, segundo Hauke (2006), a comunicação não desenvolvida é uma barreira cultural objetiva à GC. Nas respostas colhidas na pergunta aberta, dois fatores ligados à liderança surgem entre as barreiras mais citadas pelos respondentes, a falta de tempo e o foco no resultado imediato. É importante ter em vista que cabe ao líder gerir o tempo de modo que os funcionários possam ter a oportunidade de criar e compartilhar conhecimento, e não somente ficar todo o tempo preso a tarefas rotineiras. Da mesma forma que cabe ao líder dosar na medida correta o foco nos resultados imediatos que a organização precisa com a atenção que deve ser dispensada a atividades de GC que promoverão inovação dos processos em serviços e, consequentemente, garantirão um resultado melhor para empresa no futuro.

A maioria dos participantes da pesquisa apontou que no Banco Beta os funcionários não têm autonomia para tomada de decisões e não têm liberdade para inovar durante o horário de trabalho, sendo assim, constata-se que o elemento autonomia consiste-se numa barreira à GC para a inovação nesta organização. Rogers (2017) destaca a importância de que os funcionários tenham autonomia para inovar. Abdi et al. (2018) concluíram que nas organizações em que os colaboradores têm maior autonomia existe uma prontidão maior para aplicação das ferramentas de GC, o que, por conseguinte, torna essas empresas mais aptas a inovar. Naqshbandi e Tabche (2018) destacam a importância do empoderamento dos colaboradores para o sucesso da estratégia de inovação. Faz-se necessário que os funcionários tenham liberdade para inovar nos seus processos em serviços e que possam tomar decisões, para que exista uma cultura organizacional favorável à GC para a inovação.

O elemento aversão ao risco também foi apontado como uma barreira importante, em especial porque, segundo a maioria dos respondentes, na organização não está claro que os erros e falhas são uma consequência do aprendizado. Para superar essa barreira é necessário que a organização promova uma cultura que, em vez de prezar pela punição dos erros e falha, reconheça esses eventos como uma oportunidade de melhorar processos e como tentativas de otimizar os resultados da empresa. Dessa forma, os funcionários se sentirão mais à vontade para tentar inovar nos processos em serviços e até mesmo para compartilhar aquilo que não funcionou da maneira esperada, para que o erro não se repita. Davenport e Prusak (2003) classificam a intolerância ao erro como um atrito que dificulta a transferência de conhecimento e soluções. Hauke (2006) afirma que a intolerância a erros é uma barreira cultural objetiva à GC. S. Robbins, Judge, e Sobral (2010) afirmam que as organizações que recompensam mais as pessoas pela ausência de falhas do que pelos bons resultados eliminam os riscos e também a inovação. Do mesmo modo, Assefa et al. (2012) concluíram, na pesquisa que desenvolveram junto ao Banco Comercial da Etiópia, que quando os funcionários são responsabilizados por qualquer falha que possa ocorrer se trabalharem fora dos procedimentos organizacionais aprovados, é menos provável que encontrem soluções novas e eficazes para trabalhar questões relacionadas.

A maior barreira apontada pelos participantes da pesquisa foi a adaptabilidade. A absoluta maioria dos 
respondentes apontou que existe medo e resistência à mudança no Banco Beta. Hauke (2006) inclui o medo de mudanças como uma barreira cultural subjetiva que afeta a GC. Igualmente, S. Robbins et al. (2010) afirmam que a cultura organizacional pode ser um passivo para a empresa por conta de alguns aspectos disfuncionais. Entre eles, os autores citam justamente a barreira à mudança, ressaltando que esse fator pode levar a organização à ruína, levando-se em consideração o ambiente que exige mudança constante para se adaptar a novos mercados, novas tecnologias e novos concorrentes.

A percepção dos respondentes é que a cultura da organização é fechada, burocrática e com excesso de normas e controle rígido. Trata-se de uma constatação preocupante, pois adaptabilidade é um dos elementos fundamentais não somente para promover a GC para inovação de processos em serviços, mas principalmente para que a organização implemente sua estratégia de transformação digital com sucesso. Porto (2013) destaca que entre os elementos que definem a capacidade de inovação da organização está possuir uma cultura aberta. Lin et al. (2014) afirmam que uma cultura burocrática exibe comportamentos orientados para a organização e excessivamente cautelosos. Seu estudo ainda revelou que a maioria das organizações governamentais e grandes empresas com uma longa história revelaram tal cultura. Abdi et al. (2018) concluíram que organizações com culturas fechadas, burocráticas, com excesso de normas e controle rígido, inibem o compartilhamento de conhecimento e tem baixa performance em inovação.

Os resultados da pesquisa permitiram identificar ações que, se implementadas, possibilitarão reforçar e estimular o elemento da colaboração, que no Banco Beta tem sido o que mais estimula a GC para a inovação de processos em serviços. Assim como ações que permitam superar as barreiras apontadas nos demais elementos: liderança, autonomia, aversão ao risco e adaptabilidade.

\section{CONCLUSÃO}

Foram identificados na literatura os elementos da cultura organizacional que se relacionam com a GC e com a inovação, a saber: adaptabilidade, aversão ao risco, autonomia, colaboração e liderança. Através da pesquisa aplicada, buscou-se verificar quais elementos da cultura organizacional atuam como barreiras ou estímulos para a GC com foco na inovação no Banco Beta. Entre os elementos que merecem atenção por terem sido apontados como barreiras à GC para inovação de processo em serviços, estão: a adaptabilidade, aversão ao risco, autonomia e a liderança. Por outro lado, a colaboração foi apontada como um elemento da cultura organizacional que tem atuado como estímulo à GC para a inovação de processos em serviços no Banco Beta.

Conclui-se, portanto, pelos resultados encontrados na pesquisa, que o Banco Beta com maior adaptabilidade, uma calibragem mais adequada na aversão ao risco, concessão de maior autonomia aos funcionários e uma liderança que valorize as iniciativas de criação e compartilhamento de conhecimento, que mantenha uma comunicação efetiva, poderá melhorar a prontidão da organização em inovar seus processos de serviços.

Recomendam-se para estudos futuros que se busque identificar com mais clareza os fatores que levam os funcionários a apresentar o medo e resistência à mudança. Uma hipótese de pesquisa pode estar relacionada à cultura organizacional forte existente no Banco Beta, por se tratar de uma organização tradicional, com muitos anos de existência e, portanto, com maior dificuldade de promover uma cultura que encare a mudança como algo positivo. Outra hipótese a ser investigada diz respeito à experiência que os funcionários têm com as mudanças na organização, considerando que traumas por processos ocorridos no passado podem afetar a percepção do funcionário com relação ao tema. Torna-se importante aprofundar as pesquisas sobre o tema, dado que o contexto atual impõe mudanças contínuas às organizações e seus colaboradores, logo, estar aberto às mudanças e ser adaptável é importante para se obter sucesso. 


\section{REFERÊNCIAS}

Abdessadak, J., Achelhi, H., \& Reklaqui, K. (2018). Innovation: The linking \& the impact of the variables "knowledge management" and "organizational culture" on the company's performance. In 2018 international colloquium on logistics and supply chain management (logistiqua) (p. 170-174). Recuperado de https://ieeexplore.ieee.org/document/8428290

Abdi, K., Mardani, A., Senin, A. A., Tupenaite, L., Naimaviciene, J., Kanapeckiene, L., \& Kutut, V. (2018). The effect of knowledge management, organizational culture and organizational learning on innovation in automotive industry. Journal of Business Economics and Management, 19(1), 1-19. Recuperado de https://journals.vgtu.lt/index.php/ JBEM/article/view/1477

Ahmadi, S., Rajabbaigy, H., \& Moghaddar, K. (2012). The relationship between organizational culture \& knowledge management in payame nour university of tehran. European Journal of Economics, Finance and Administrative Sciences(51). Recuperado de https://www.academia.edu/ 15345618/The Relationship between Organizational Culture and Knowledge_Management in Payame _Nour_University_of_Tehran

Ajmal, M. M., \& Helo, P. (2010). Organisational culture and knowledge management: an empirical study in finnish project-based companies. International Journal of Innovation and Learning, 7(3), 331-344. Recuperado de https:// papers.ssrn.com/sol3/papers.cfm?abstract_id $=1609091$

Al-Adaileh, R. M., \& Al-Atawi, M. S. (2011). Organizational culture impact on knowledge exchange: Saudi telecom context. Journal of knowledge Management, 15(2), 212-230. Recuperado de https://www.emerald.com/insight/content/ doi/10.1108/13673271111119664/full/html

Assefa, T., Garfield, M., \& Meshesha, M. (2012). The impact of organization culture on knowledge sharing among employees in commercial bank of ethiopia (cbe). In European conference on knowledge management. cartagena (eckm). Recuperado de https://pdfs.semanticscholar.org/ b143/8569b9b06767169f30ed97e0cabfa177e0b9.pdf

Cameron, K. S., \& Quinn, R. E. (2006). Diagnosing and changing organizational culture: Based on the competing values framework. São Francisco: John Wiley \& Sons.

Chang, C. L.-h., \& Lin, T.-C. (2015). The role of organizational culture in the knowledge management process. Journal of Knowledge management, 19(3), 433-455.

Choy, S., Lee, W. B., Cheung, C. F., \& Shim, G. (2005). Development of a knowledge management culture assessment tool with applications in aviation industry. Journal of Information $\& 5$ Knowledge Management, 4(3), 179-189. Recuperado de https://www.worldscientific.com/doi/abs/ 10.1142/S0219649205001158

Corfield, A., \& Paton, R. (2016). Investigating knowledge management: can $\mathrm{km}$ really change organisational culture? Journal of Knowledge Management, 20(1), 88-103. Recuperado de http://oro.open.ac.uk/44928/

Davenport, T. H., \& Prusak, L. (2003). Laurence. conhecimento empresarial: como as organizações gerenciam o seu capital intelectual (14a. ed.). Rio de janeiro: Elsevier.

Dias, R. (2013). Cultura organizacional: construção, consolidação e mudanças. São Paulo: Editora Atlas SA.

Donate, M. J., \& Guadamillas, F. (2011). Organizational factors to support knowledge management and innovation. Journal of knowledge management, 15(6), 890-914. Recu- perado de https://www.emerald.com/insight/content/doi/ 10.1108/13673271111179271/full/html

Hauke, A. (2006). Impact of cultural differences on knowledge transfer in british, hungarian and polish enterprises (v. 50; Relatório Técnico). Nota di Lavoro. Recuperado de https://www.google.com/url?sa=t\&rct= $\mathrm{j} \& \mathrm{q}=\& \mathrm{esrc}=\mathrm{s} \&$ source $=$ web\&cd $=\&$ ved $=2$ ahUKEwjL9 2GrujvAhXRHrkGHb1QC-AQFjABegQICRAD\&url= https $\% 3 \mathrm{~A} \% 2 \mathrm{~F} \% 2$ Fageconsearch.umn.edu $\%$ 2Frecord\%2F12072\%2Ffiles\%2Fwp060050.pdf\&usg= AOvVaw0P1ISJ2kEAaFiLaYroj_ew

Hofstede, G., Hofstede, G. J., \& Minkov, M. (2010). Cultures and organizations: Software of the mind (v. 3). Mcgraw-hill Education.

Lamproulis, D. (2007). Cultural space and technology enhance the knowledge process. Journal of Knowledge Management, 11(4), 30-44. Recuperado de https://www.emerald.com/insight/content/doi/10.1108/ $13673270710762693 /$ full/html

Lin, P.-C., Ho, H.-Y., \& Lu, M.-H. (2014). Effects of knowledge management and corporate culture on organizational innovation climate. Revista internacional de sociología, 72 (2), 43-55. Recuperado de https://pdfs.semanticscholar .org/5f72/c6c6ac45e1f97aa540077ae64694e5de99ef.pdf

Naqshbandi, M. M., \& Tabche, I. (2018). The interplay of leadership, absorptive capacity, and organizational learning culture in open innovation: Testing a moderated mediation model. Technological Forecasting and Social Change, 133, 156-167. Recuperado de https://www.sciencedirect.com/ science/article/pii/S0040162517307357

Nonaka, I., \& Takeuchi, H. (1997). Criação de conhecimento na empresa. Rio de Janeiro: Elsevier Brasil.

Organização para Cooperação Econômica e Desenvolvimento. (2005). Manual de oslo: diretrizes para coleta e interpretação de dados sobre inovação (3a. ed.). ARTI/FINEP. Recuperado de https://www.finep.gov.br/images/apoio-e -financiamento/manualoslo.pdf

Paliszkiewicz, J. O. (2010). The relationship between social perspective and knowledge management. International Journal of Innovation and Learning, 7(4), 450-466. Recuperado de https://www.researchgate.net/ publication/264835617_The_relationship_between _social_perspective_and_knowledge_management

Pohontu, A., Istrate, C., \& Herghiligiu, I. V. (2016). An innovative learning by sharing model for enhancing long term development inside corporate organizations. In European conference on knowledge management (p. 1063-1070). Northern Ireland, UK. Recuperado de https://www.researchgate.net/publication/ 309266609 AN INNOVATIVE LEARNING BY SHARING $\bar{G}$ MODEL_FOR_ENHANCING_LONG

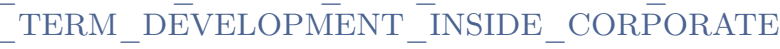
ORGAN̄IZATIONS

Porto, G. (2013). Gestão da inovação e empreendedorismo. Rio de Janeiro: Elsevier.

Puryantini, N., Rofikotul, A., Tjahjadi, B., et al. (2018). The association of knowledge management, organization culture, and innovation with organizational performance: A case at study institute research xyz. Jurnal Akuntansi dan Keuangan, 20(1), 39-52. Recuperado de http://jurnalakuntansi .petra.ac.id/index.php/aku/article/view/20850

Rivera-Vazquez, J. C., Ortiz-Fournier, L. V., \& Flores, F. R. (2009). Overcoming cultural barriers for innovation and kno- 
wledge sharing. Journal of knowledge management, 13(5), 257-270. Recuperado de https://www.emerald.com/insight/ content/doi/10.1108/13673270910988097/full/html

Robbins, N. B., Heiberger, R. M., et al. (2011). Plotting likert and other rating scales. In Proceedings of the 2011 joint statistical meeting (v. 1, p. 1058-1066). Recuperado de http://www.asasrms.org/Proceedings/y2011/Files/ 300784_64164.pdf

Robbins, S., Judge, T., \& Sobral, F. (2010). Comportamento organizacional: teoria e prática no contexto brasileiro (14a. ed.). São Paulo: Pearson Prentice Hall.

Rogers, D. L. (2017). Transformação digital: repensando o seu negócio para a era digital. São Paulo: Autêntica Business.

Schein, E. H. (2017). Cultura organizacional e liderança. São Paulo: Atlas.

Souza Neto, J., Santos, D. L. N., \& Orlandi, T. R. C. (2014). Inovação: estratégia, gestão e cultura. Edição do Kindle.

Takeuchi, H., \& Nonaka, I. (2008). Gestão do conhecimento. Porto Alegre: Bookman.

Tang, L.-L., \& Yeh, Y.-L. (2015). Effect of organizational culture, leadership style, and organizational learning on organizational innovation in the public sector. Journal of Quality, 22(5), 461481. Recuperado de https://www.researchgate.net/ publication/285124864_Effect_of Organizational _Culture_Leadership_Style_and_Organizational _Learning_on_Organizational_Innovation_in_the _Public_Sector_462_Effect_of_Organizational_Culture _Leadership_Style_and_Organizational

Tigre, P. B. (2014). Gestão da inovação: a economia da tecnologia no brasil (2a. ed.). Rio de Janeiro: Elsevier.

Yee, Y. M., Tan, C. L., \& Ramayah, T. (2017). Connect the silos: Knowledge management, absorptive capacity, leadership styles, organisational cultures. In International conference on intellectual capital and knowledge management and organisational learning (p. 310-315). Recuperado de https://books.google.com.br/books $? \mathrm{id}=3 \mathrm{blDDwAAQBAJ} \& \mathrm{pg}=\mathrm{PA} 310 \& \mathrm{lpg}=\mathrm{PA} 310 \& \mathrm{dq}=$ Connect + the + silos $:+$ knowledge + management,+ absorptive + capacity, + leadership + styles, + organisational + cultures $+2017 \&$ source $=$ bl\&ots $=$ YdwD0OJ25H\&sig $=$ ACfU3U0XYVBsjmIBSAd4nFEr51V4uEiHBg\&hl= pt-BR\&sa $=$ X\&ved $=2$ ahUKEwiSzIj -lrfjAhWXIbkGHddzD44Q6AEwAHoECAkQAQ\#v= onepage $\& \mathrm{q} \& \mathrm{f}=$ false

Zia, S., \& Shafiq, M. (2017). Innovation and knowledge management: A literature review and research framework. Journal of Quality and Technology Management, 13(1), 99116. Recuperado de http://pu.edu.pk/images/journal/iqtm/ PDF-FILES/006-V_XIII_I,June2017.pdf

Como citar este artigo (APA):

Carneiro, H. L. B. \& Streit, R. E. (2021). O impacto da cultura organizacional na gestão do conhecimento para a inovação de processos em serviços. AtoZ: novas práticas em informação e conhecimento, 10(2), 78 - 88. Recuperado de: http://dx.doi.org/10.5380/atoz.v10i2 .78259 